\title{
THE EXTENDED FUNCTIONS OF STRATEGIC CONTROLLING IN RELATION TO THE VALUE CREATION OF SUSTAINABLE DEVELOPMENT
}

\author{
Zoltán Zéman
}

Szent István University, Faculty for Economics and Social Studies, Finance and Accounting Institute, Gödöllő, Hungary

\begin{abstract}
Strategic planning is generally performed internally and particularly by the organization. Another, lesser discussed issue of non-adequate strategic planning is that corporate management is unable to outline its long term resources without it. Supporting and ensuring the feasibility of individual set-ups of this function, which is probably the most important of all, is without doubt an expanded task of strategic control. From the managers' point of view, the time spent on managing and controlling the individual tasks is also a type of resource to be managed. The strategy is the subject of development on a regular basis - that is, also an expanded task of strategic control - and managers should always take it into consideration alongside the operational tasks, since the design, development and implementation of strategy are affected by high-risk events of the external environment. The mapping of sustainable development at the microeconomic level is part of corporate social responsibility. Sustainable development requires global thinking and action. This is reflected in the fact that, in their economic decisions, businesses should strive for the economical use of scarce resources, achieve a balance between resource development and preservation, and ensure an appropriate dialogue, the so-called "resource" of stakeholders. The aim of the paper is to demonstrate the role of controlling in sustainable development using theoretical modelling.
\end{abstract}

Keywords: management accounting, sustanibility, strategic controll

\section{Introduction}

Companies must increasingly recognize that good environmental performance results in positive economic performance. According to Keszi Szeremlei and Magda (2015) the problems of sustainable development are system-based. Answers to local challenges cannot be provided without the knowledge of the wider context of global processes. The relationship between environmental and economic performance is therefore of paramount importance. Economic development expands the availability of work and the ability of individuals to secure an income to support themselves and their families. Economic development includes industry, sustainable agriculture, as well as integration and full participation in the global economy. Social and economic developments reinforce and depend on one another for full realization (Magda, 2013). There are two views on this topic. One of the traditional approaches is that if companies increase their environmental performance, it will result in higher costs and a reduction in the economic performance of companies. Environmental performance can only be improved at the expense of economic efficiency, this is the so-called "win-lose" paradigm. The other view is related to environmental efficiency, according to which the environmental pollution is a form of business that does not operate in an economically efficient way (Royce and Hansen, 2008).

This approach is expressed by the "win-win" paradigm, as both economic and environmental efficiency appear in the performance of the company. An increasing number of management companies in international companies hold this view, as evidenced by a survey of 50 large companies, which shows that the two thirds of the companies involved in the survey have a sustainable development perspective (Zeman and Lentner, 2018). The results of the survey are presented in Figure 1.

At the same time, it can be said that the "win - win" paradigm is not expected to be achieved by the company alone, but that proper regulation is also needed to improve the environmental performance of an enterprise strategy as an element of sustainable development. In addition to the regulation, companies also need to recognize their CSR in maintaining the quality of their operating environment and in environmentally conscious corporate management (Lacy et al., 2013).

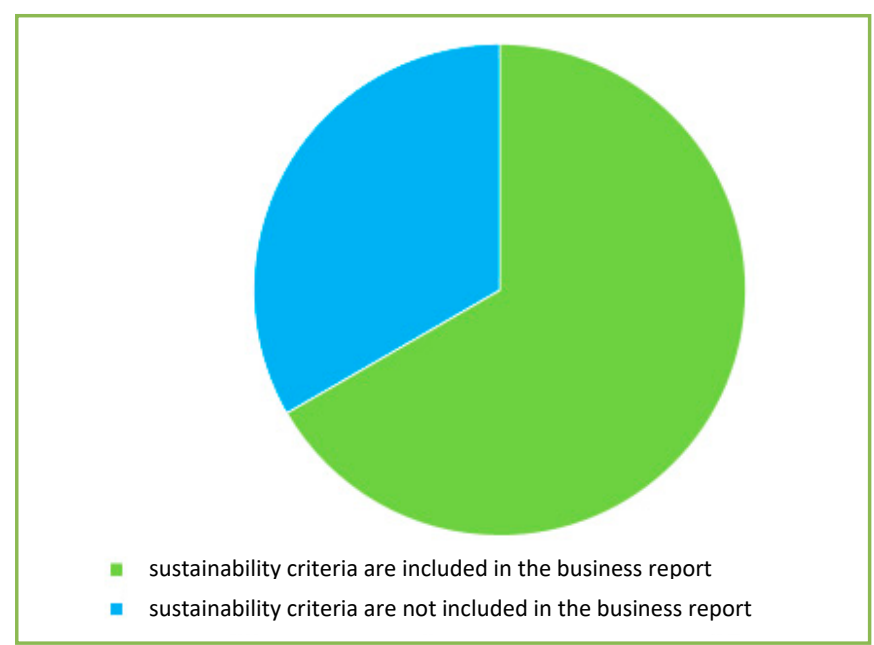

Figure 1 Proportion of sustainability criteria in business report Source: own construction Zeman-Lentner, 2018

The companies' sustainability-related tasks must also be reflected in the strategy, whose continuous support and realization can be accomplished by strategic controlling (Böcskei et al., 2015).

\section{Material and methods}

Strategic controlling also supports the development of a benchmark system applicable in its body of instruments. Strategic management, as a somewhat service activity, is designed to measure and monitor the achievement and effectiveness of goals, and thus to analyze the efficiency 
of the entire organization. Developing these, i.e. the coordination of such activities of the management (selection of factors), is also one of the extended tasks of strategic controlling. A particular attention must be paid to the value chain approach in management which again reflects a new orientation in strategic, financial and managerial accounting (Moon et al., 2011; Pondeville et al., 2013).

Accordingly, revenue and expense accounts should be taken into consideration not only in that particular organization, but throughout the total lifecycle of a product. Strategic accounting established two developmental directions and a practical methodology:

$\square$ with regard to the political content of accounting - where two accounting principles are taken into consideration (the principle of continuance of business and the principle of prudence),

$\square$ with regard to a value-driven approach towards accounting of corporate processes and the development of a responsibilitybased accounting system.

The long-term approach - target value control - applicable in accounting-oriented management can assist sound managerial decisions and feasible visions. Concurrently, the appearance of this type of strategic orientation in accounting already prognosticates the future appearance and technological application of managerial decision support systems. Therefore, the extended task of strategic control may be to support the best selection of market and customer segments, and to identify the processes and resources that are needed to effectively create corporate values. Needless to say, the implementation of all aforementioed tasks is based on strategic management accounting (Gábor and Zéman, 2016).

The study examines a new approach to accounting and sustainability and its integration into value-based management, based on a theoretical approach. In addition, the study examines ways to integrate sustainability into operational and strategic controlling. In examination of the former approach, the Balanced Scorecard model was used, while in the strategic approach, the approach of controlling regulator was applied. Finally, necessary conditions for an Eco-controlling background are presented in the study.

\section{Results and discussion}

The innovative elements of the strategic accounting management concept are as follows: $\square$ the growing role of intellectual property in corporate values,

$\square$ the emergence of environmental consciousness and energy awareness in accounting,

$\square$ integrated accounting performance measurement,

$\square$ coordination of strategic maps with operational statements,

$\square$ value orientation,

$\square$ consistency of internal business statements with long-term objectives - appearance of sustainability (CSR) in the alignment of real and nominal processes,

$\square$ the appearance of sharing economy.

By creating a strategy and selecting and implementing it from different strategic viewpoints, the management fulfills its basic objective to increase the value of ownership, which results in a positive added value to the ownership. An additional prerequisite for maximizing the shareholder value is the long-term sustainability of the growth of value (Mahama, 2006).

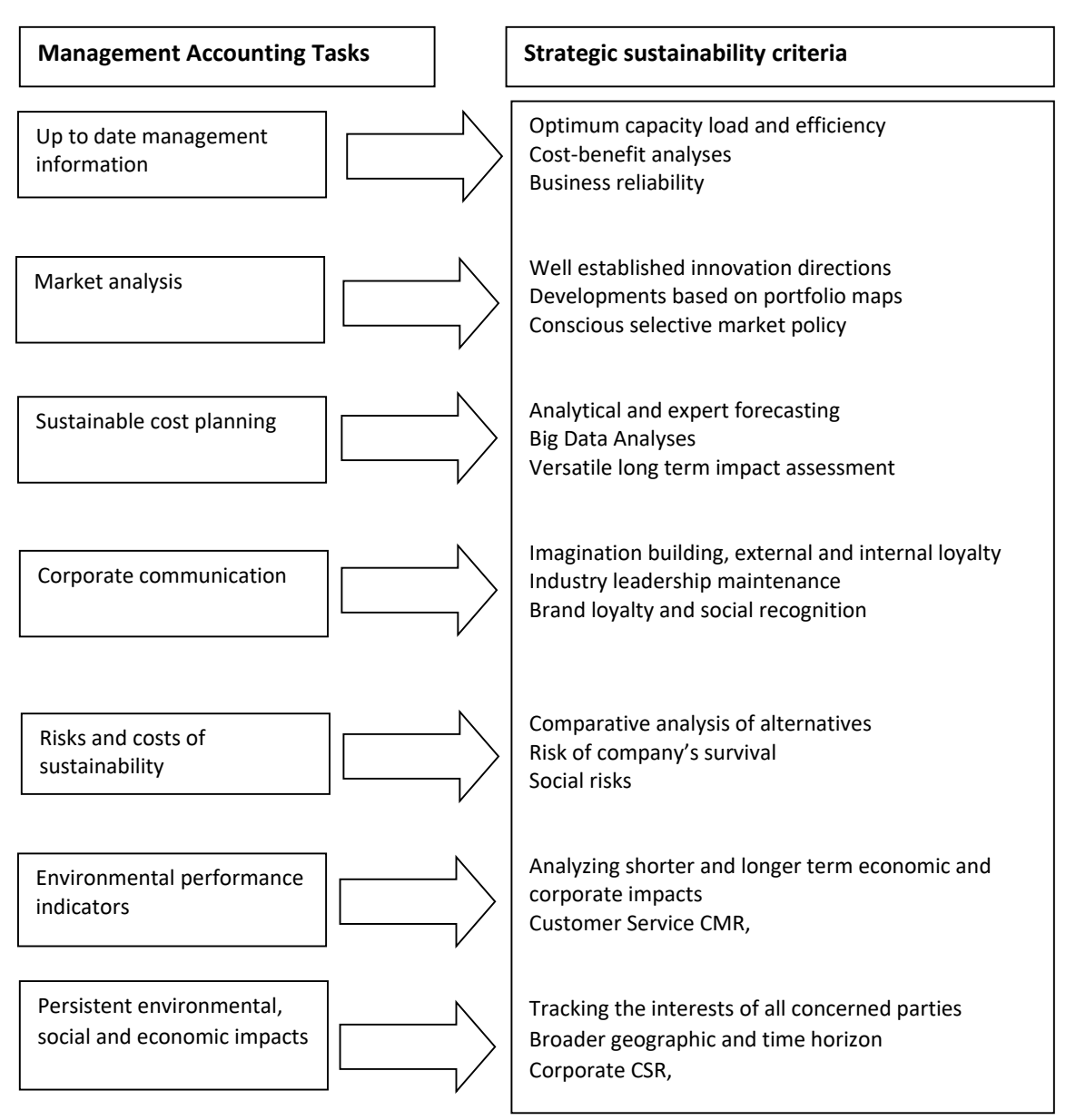

Figure 2 Functional Scheme for Sustainable Management Accounting (1) Source: own construction
Figure 2 summarizes the bases of the Anglo-Saxon approach that had already defined the management accounting approach in the 60 's. The objective was to demonstrate the comparability between the current trends of the development and the starting-points of the past. Therefore we could better picture the innovative elements that have already been confirmed by the development of practical techniques for management accounting.

However, due to environmental changes, the expectations towards controlling have become even greater; new areas dealing with issue have been added to the traditional tools of controlling, such as project and IT controlling, the relationship between risk management, internal control and controlling, harmonization of interests and goals in differentiated functionalities, effective support for the relations of financial functionality, the role of controlling in sustainability, etc.

The magnitude of the risks and threats to sustainability and the number of responses to this make it necessary, as economic, environmental and social impacts, investment decisions and market relationships are crucial. 
The framework is also able to compare the sustainability performance of the company on time and compare it with other companies. The GRI (Global Reporting Initiative, GRI) continuously reviews and develops the reporting framework, and as a result, the framework has been revised several times. Companies must enforce principles in the content, quality and boundaries of the report setting. The purpose of using and enforcing the principles is to ensure the transparency of the report. One group of principles represents the topic of the report and the indicators, while the other group provides the quality and proper presentation of the reported information. In determining the content of the report, the principles of "materiality" and "consistency", known from accounting, should be respected (Schaltegger et al., 2000, 2009).

The principle of materiality in sustainability reports refers to the consideration of "economic, environmental and social impacts that go beyond the threshold above which the organization, in meeting its present needs, may deprive future generations of their ability to meet their own needs" (GRI, 2013). There are two differences in the interpretation of the principle. One difference is that the materiality threshold cannot be quantified, it must be defined by the company on the basis of the concept of sustainable development, and the other one is that the company's economic, environmental and social impacts are much wider. The principle of completeness means that the boundaries of the report must be defined in a way to fully cover the economic, environmental and social impacts of the activity carried out by the enterprise.

Several conceptual models have already dealt with complementary sustainability accounting for management accounting related to traditional financial accounting, in which the key elements of business integrity, business ethics, social utility, and environmental protection were formulated, addressing financial and economic impacts within and outside the company. In the next theoretical model, the efficiency issues that need to be linked to sustainability and other ecological criteria are outlined.

Effective operation of management accounting enables the selection of priorities of each target area and thus the development of competitive advantageous alternatives through the examination of their functionalities and the strength of their relations. Consequently, the development trends have an equilibrium effect on the control of managerial accounting at both operational and strategic levels. The emergence of new business models is more and more dynamic, and it is increasingly demonstrating their competitiveness.

Business analytics, internet penetration, and service-oriented development of infocommunication, are becoming increasingly determinant in corporate operations.

These challenges require the balance of the management-supporting information systems, therefore the basic approach and basic model of BSC is crucial in both the operational and strategic areas of management accounting. By this, the information priority of the individual areas is better illustrated, and the issue of financial efficiency can also be highlighted in the system efficiency. Figure 3 illustrates a possible (but not complete) set of criteria. Financial aspects:

$\square$ synchronizing rules and norms with financial performance,

$\square$ taking financial criteria into account (e.g. in assessing investment risks)

$\square$ design of financial plans for liquidity (short and long term), focusing on extreme cash flows,

$\square$ expected profit or loss, presenting plan-fact values, showing the cost and revenue sides,

$\square$ budget from the viewpoint of corporate interest and functions (operational management accounting, financial performance measurement).

Operational processes:

$\square$ value stream mapping,

$\square$ reconciliation and utilization of synthetics and analytics from real and up-to-date data in the operation of management processes, as with the growth of data quantity, data quality should also be in focus.

$\square$ the establishment of the basics of energy and cost efficiency in relation to quality management,

$\square$ ERP (Enterprise Resource Planning) system, complex management system at both operational and strategic levels,

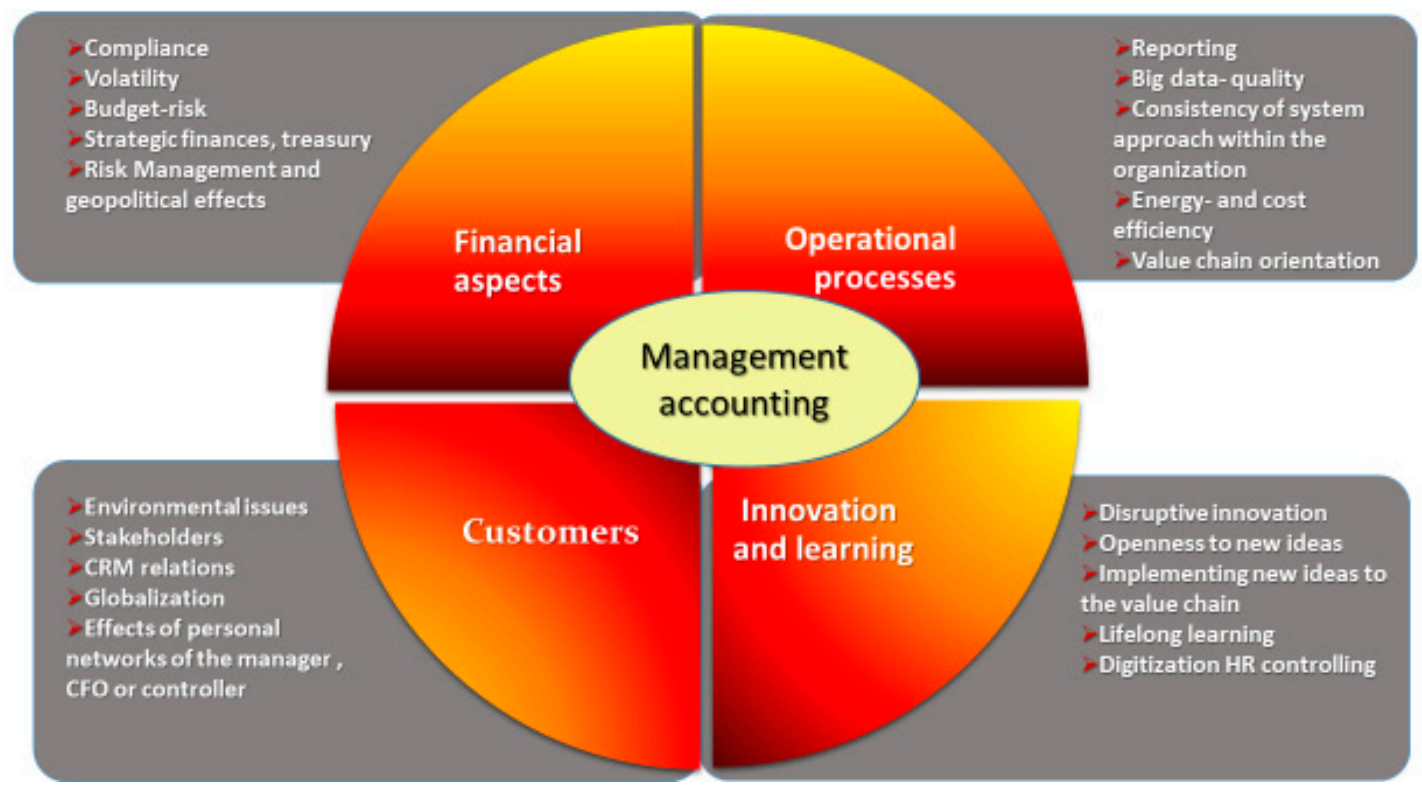

Figure 3 Scorecard effect on management accounting Source: own editing 
$\square$ value chain approach in financial and management accounting.

Customers:

$\square$ environmental issues, primary focus on the definition of the microenvironment; managing investor - shareholder - stakeholder interests

$\square$ manager/CF0: internal organizational relationships and external customer relations, determination of measurable factors for strategic management accounting,

$\square$ operation of CRM (Customer Relationship Management) systems, connecting customer relations to management accounting,

$\square$ defining globalization parameters at the level of international customer relations.

Innovation and learning:

$\square$ Adaptability of innovative thinking into design, adapting innovation to the value chain,

$\square$ disruptive innovation - reconciliation of the nature and role of controlling and innovation with the expected performance taken into consideration,

$\square$ the appreciation of digitization and HR control in management,

$\square$ administrative management development in organizational, financial and accounting culture,

$\square$ lifelong learning.

The impact of the use of dynamic new business models on competitiveness has already been mentioned. There is a competitive advantage if the value creation is sustainable and does not only exist in the short term. The question of timeliness is important, since if it is not taken into consideration, one can easily fall into the trap of implementing a strategy that will only create value in the short term. Sustainability is not independent of the industry in which the company operates. It is affected by the lifecycle of products or services and the appropriate introduction of individual products or services to a new market, thus placing their life cycles on a different path.

In the marketing literature, it is often stated that the products that are, for example protected by patents, have high entry barriers or an advantage in their geographic location; they generally have a long life curve. They are therefore relatively protected from the pressure of competitors, and the competitive advantage is maintained in the longer term. Regarding products with normal life curves, the competitive edge is generally sooner eliminated, and products with short life cycles (e.g. cellphones) show the lack of, or minimal competitive advantage that is very difficult to sustain, as competitors are able to copy the novelty in a short time. In this instance, the company has a constant obligation to renewal. $R \& D$ control and quality management play a determining role in corporate functions. Therefore, in these processes in terms of both production and development issues - productivity and efficiency indicators are highly determinant, which means that the extent of company resources is utilized, namely the value of the invested assets or working capital used for a single unit of revenue (or the production value), or the amount of capital invested, the quantity of labor force, or the expense of earned revenues. For such indicators, the basis of the comparison and the subject of the comparison are interchangeable. For example, not only we can compare assets and capital (straight indicator) to revenue, but vice versa, resources can also be compared to revenue (reverse indicator). The latter case expresses capital or resource requirement, which is also the subject of decision-making in operational financial controlling that has an effect on the development and operation of management accounting.
Efficiency issues are the key factors in system-level operational efficiency in management accounting. This indeed includes the contents of the decision-oriented reporting system, which raises qualitative, quantitative and data logistic issues. It therefore influences the consecutive elements of the management information system and the implementation of their functional connection system.

Environmental (green) accounting is the collection, grouping, processing and control of environmental data. Consequently, the most important task is to take account of the changes in the natural resources of the enterprise during the economic activity and to identify the environmental costs and causes. The tools of green accounting are the preparation of environmental accounting, ecology balance and cost benefit analysis (impact assessment); the methodology differs from company to company, and is adapted to the company's activities (Mathews, 1997).

In environmental accounting, there are two trends (approaches) - pale green and dark green. The pale green approach requires companies to disclose general information, costs and obligations related to the environment. Information on this approach can be provided from financial accounting data. Disclosure is achieved by supplementing the financial reports. The dark green approach means a broader interpretation of environmental accounting, as it involves taking the costs and results of all the impacts that an enterprise has on the natural environment in to account and publishing them (Mathews, 1997).

Eco-controlling is a self-regulating system for environmentrelated activities, including the acceptance and correct interpretation of environmental signals from the market. Eco-controlling must be integrated into the company's control system, as this is the only way to ensure the relationship between controlling the environment and controlling other sub-processes. Strategic and operative controlling can also be found within eco-controlling. Strategic eco-controlling determines the future development of the company's environmental performance, and it is an integral part of the company's future performance. It covers the entire product life cycle from production planning and product development - through purchasing, production and sales - to use and after-use disposal. Operational ecocontrol provides the environmental information that is needed to make environmental decisions and to prepare environmental reports. Operational eco-control includes: environmental accounting and eco-balancing.

Among the new trends and modes of action listed, the issue of sustainability should be highlighted, which needs two-way approach in the regulatory circle of controlling. One of the main directions studied by both national and international researchers is the sustainable adherence of baseline data and natural objects into production, such as the relationship between environmental issues, technological background, and closed-loop material systems (Boons et al., 2013).

The other direction is basically establishing financial and economical sustainability that are applicable in these processes - depending on real and nominal processes and relationships - within the company; i.e. creating long-term financial and economic operations, synchronizing output and input processes. Needless to say, in order for this to be financially viable (i.e. the quality and optimization requirements of liquidity, creditworthiness and profitability are met), the company must enter a new stage of development and advancement, which should include opening up to various co-operations and the possibilities of mutual sharing. From the strategic viewpoint, it is crucial for the company to find out the market conditions and how it can achieve its objectives in competition, therefore, the usage and analysis of strategic indicators should be considered with greater emphasis. 


\section{Environmental expectations}

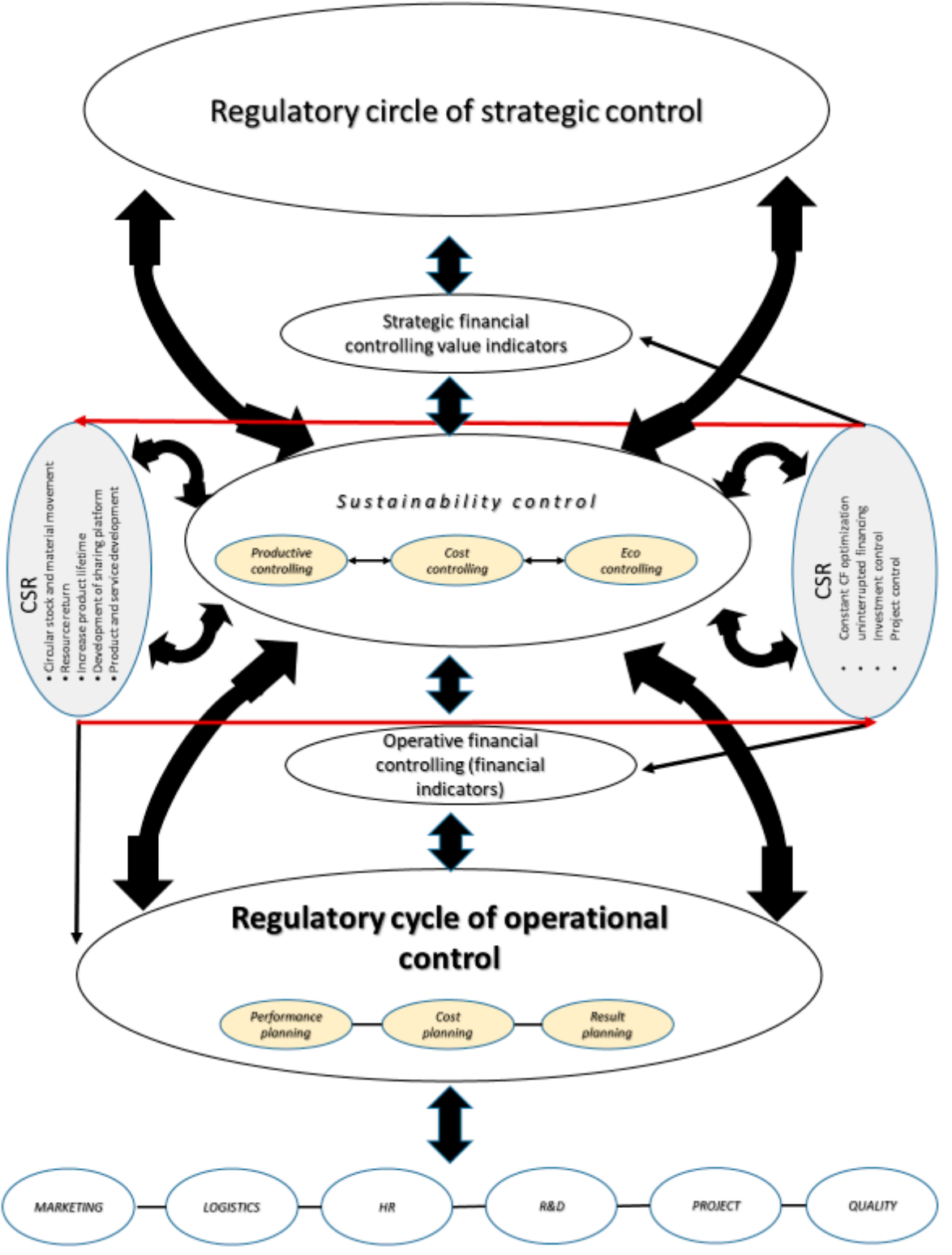

Figure 4 The relations between the controlling system and the sustainability control mechanism Source: own editing

It must be pointed out that internal control processes are multifaceted due to their functionality. This results in production control and cost control (due to marginal additional costs), eco-controlling, $R$ \& D \& I (Research, Development, Innovation) controlling becoming unavoidable, when discussing sustainability. When designing a $R$ \& D control area, it is necessary to clearly locate the development costs of a product in the production cycle, that is, connecting cost-efficiency with serial production (as development costs take up about $30 \%$ of total costs on average). Each of these fields can provide basic information through an interface module that provides a basis for financial issues. Financial engagement is reflected in continuous cash flow optimization, uninterrupted financing, ongoing investment issues and analyses, and it is also reflected in the need for continuous returns. Apparently, if these feedback processes are interlocked in a circular way, they form a closed system (the general controlling cycle essentially treats and processes economic data in a closed system in its basic methodology), which informs the management to match controlling principles with business objectives, in order to make them feasible. It can be stated that the control mechanism of the controlling cycle can thus provide for the coordination and feedback of this process in order to move towards the economic and financial sustainability of business operation (Boons et al., 2013).

It is well known that the key issue of sustainability is the continuous recycling and returning, in connection with minimizing the use of raw material.

Regarding this issue, the feasibility of financial objectives and their priorities is of fundamental importance. Consequently, automated control (although it is programmable) cannot be operated with it. From a financial point of view, it always requires management decision, particularly when defining and validating the priorities within our objectives, which is also exposed to environmental changes. With respect to the time factor, the cash flow optimization, the temporal change in cash flows, and the issue if financing (either internal or external) is of high importance.

It is also necessary to point out the importance of the availability of an optimal financial background, while its assurance is also the responsibility of the management. The relations between the company value and performance indicators of strategic financial controlling and sustainability control may be in assistance of such management tasks.

Consequently, the information provided by the management accounting (based on aggregated/synthesized data) depending on the decision needs and necessities should be constantly shaped, in order to show and analyze other contexts.

Eco-controlling can only meet the tasks listed above, if it complements the existing corporate information system with environmental information. The management accounting system developed with environmental protection criteria has an important task in this.

\section{Conclusion}

Based on the theoretical model, the role of management and controlling systems can be clearly seen in long-term sustainability. Eco-controlling and strategic management accounting help long-term sustainability to a great extent. As a result, controlling will also link management information to sustainable enterprise decisions in the field of automation and robotization. As a result, the controlling system serves as a bridge between economic sustainability and ecological sustainability. In summary, controlling uses a shield for corporate mapping of megatrend effects. 
Summarizing the results, it can be determined that these are the core trends of strategic accounting and strategic control:

$\square$ In the business analysis of the profitability of sales channels (consistency of price and demand), instead of analyzing the profitability of the products, value analysis, value chain orientation - the maximization of capacity, the determination of the flexibility factors and the support of the management functions by management accounting are emphasized.

$\square$ A shift to predictive accounting for analyzing increased data sets (timedriven, dynamic). Combined and upgraded management accounting methods (e.g. modernization of cost allocation systems).

$\square$ Emergence of strategic management accounting, energy and cost efficiency. New trends in management accounting (e.g. green accounting, eco-controlling, value-oriented control, and sharing economy).

$\square$ Monitoring its harmony with strategy: the controlling task is to support the strategic goals and the innovation strategy, through which we can measure and connect the efficiency and quality control factors of individual projects to strategy through the index system, therefore realization takes place in production.

$\square$ Fit to a life cycle and process:

1/ the performance indicators of the project control system should be aligned with the innovation lifecycle of the projects,

2/ assigning different decision points to different phases of product development (e.g. basic research, prototype production),

3/ aligning cost-financial aspects of the performance indicators to the efficiency indicators.

$\square$ One of the key tasks of quality management is the qualitative and quantitative support of resources during innovation. When designing a R \& D control area, it is necessary to clearly locate the development costs of a product in the production cycle: that is connecting cost-efficiency with serial production.

Future research could analyze empirically the dynamics of Management Accounting and Control Systems in the relationship between sustainable innovation and organizational performance.

\section{References}

BOONS, F. - MONTALVO, C. - QUIST, J. - WAGNER, M. 2013. Sustainable innovation, business models and economic performance: An overview. In J. Clean. Prod., 2013, no. 45, pp. 1-8.

BÖCSKEI, E. - FENYVES, V. - ZSIDÓ, K. - BÁCS Z. 2015. Expenced Risk Assessement Annual Report versus Social Responsibility. In Sustainability, vol. 7, 2015, no. 8, pp. $9960-9972$.
BURNETT, R.D. - HANSEN, D.R. 2008. Ecoefficiency: defining a role for environmental cost management. Accounting, organizations and society : an international journal devoted to the behavioural, organizational and social aspects of accounting. ZDB-ID 83016-1, vol. 33, 2008, no. 6, p. 551-581. ISSN 0361-3682.

LOPEZ-VALEIRAS, E. - GOMEZ-CONDE, J. - NARANJO GIL, D. 2015. Sustainable Innovation, Management Accounting and Control Systems, and International Performance. In Sustainability, 2015, no. 7, pp. 3479-3492. D0I:10.3390/SU7033479.

GÁBOR, Á. - ZÉMAN, Z. 2016. The Encounter of Project Control and Innovation in a New Bussiness Modell - or, Book-Save-Sleep Wisely. In International Journal of Innovation and Research in Educational Sciences, vol. 3, 2016, no. 1, pp. 1-8.

GRI. 2013. Sustainability Reporting Guidelines G4: Reporting Principles and Standard Discloures. Amsterdam, The Netherlands : Global Reporting Initiative, 2013.

KESZI SZEREMLEI, A. - MAGDA, R. 2015. Sustainable production and consumption. In Visegrad Journal on Bioeconomy and Sustainable Development, vol. 4, 2015, no. 2, pp. 57-61.

LACY, P. - ROSENBERG, D. - DREWELL, Q. - RUTQVIST, J. 2013. 5 Business Models That Are Driving. In The Circular Economy, 2013.

MAGDA, R. 2013. Difficulties in sustainability and land utilisation. In Visegrad Journal on Bioeconomy and Sustainable Development, vol. 2, 2013, no. 1, pp. 15-18.

MAHAMA, H. 2006. Management control systems, cooperation and performance in strategic supply relationships: A survey in the mines. In Manag. Acc. Res, 2006, no. 17, pp. 315-339.

MOON, J. - GOND, J. P. - GRUBNIC, S. - HERZIG, C. 2011. Management Control for Sustainability Strategy; CIMA Research Executive Summary Series 7; Chartered Institute of Management Accountants : London, UK.

MATHEWS, M. R. 1997. Twenty-Five Years of Social and Environmental Accounting Research: Is There a Silver Jubilee to Celebrate? In Accounting Auditing and Accountability Joumal, vol. 10, 1997, no. 2, pp. 481-531.

PONDEVILLE, S. - SWAEN, V. - DE RONGÉ, Y. 2013 Environmental management control systems: The role of contextual and strategic factors. In Manag. Acc. Res., 2013, no. 24, pp. 317-332.

SCHALTEGGER, S. - BURRIRT, R. L. 2009. Sustainability Accounting for Companies: Catchphrase or Decision Support for Business Leaders? In Joumal of World Business, 2009. doi: 10.1016/j.jwb.2009.08.02

SCHALTEGGER, S. - BURRITT, R. L. 2000. Contemporary Environmental Accounting: Issues, Concepts and Practice. Sheffield : Greenleaf Publishing, 2000.

ZÉMAN,Z. - LENTNER, CS. 2018).The changing role of going concern assumption supporting management decisions after financial crisis. In Polish Journal of Management Studies, no. 1, 2018, pp. 428-440.

ZÉMAN, Z. - TÓTH, A. 2018. Strategic Financial Controlling and Management. Academic Publisher.

\section{Contact address}

Zoltán Zéman, professor, Head of Institute, Szent István University, Faculty for Economics and Social Studies, Finance and Accounting Institute, Páter K. srt. 1, 2100 Gödöllő, Hungary, e-mail: zeman.zoltan@gtk.szie.hu 